\title{
Edisi Tahqiq Risalat Al-Isti'arat Karya Syeikh Ahmad Al-Fatani
}

\author{
Amer Hudhaifah bin Hamzah ${ }^{1} \&$ Salmah Ahmad ${ }^{1}$ \\ ${ }^{1}$ Fakulti Pengajian Islam, Universiti Kebangsaan Malaysia \\ *Corresponding Author: amerukun@gmail.com
}

\begin{abstract}
Article history
Received: 2015-10-19

Received in revised form: 2016-01-07

Accepted: 2016-01-07

Abstract

The book Risalat al-Isti c arat which written by Sheikh Ahmad al-Fatani is among the earliest works of Malay scholars in the field of Balaghah. As a work of the earliest, it should be preserved and maintained its authenticity so the secrets it contains are not lost by modernization. According to Wan Mohd Shaghir, this book is among the works of Sheikh Ahmad al-Fatani that used to be famous and frequently used in Arabic language studies. Therefore, the absence of this book in market and libraries must be avoided by editing manuscript of the book which placed in local manuscript repositories. Consequently, an edited edition of Risalat al-Isti c arat should be published thus can be beneficial to students and researchers to read, review and conduct further research.
\end{abstract}

Keywords: Risalat al-Isti c arat, Tahqiq Edition, Work of Syeikh Ahmad, Ilm al-Isti c arat, Matn al-Bayan.

\begin{abstract}
Abstrak
Kitab Risalat al-Isticarat karya Syeikh Ahmad al-Fatani merupakan sebuah karya ulung yang dihasilkan oleh ulama Melayu dalam bidang balaghah. Sebagai sebuah karya ulung, ia sewajarnya dilestarikan dan dijaga keasliannya agar 1001 rahsia yang dikandungnya tidak hilang ditiup taufan permodenan. Wan Mohd Shaghir menyatakan bahawa karya ini merupakan salah sebuah karya Syeikh Ahmad al-Fatani yang pernah menjadi terkenal dan banyak digunakan dalam pengajian-pengajian bahasa Arab. Sehubungan itu, apabila tidak didapati sebarang naskhah bagi karya ini dijual ataupun boleh diperolehi dengan mudah di mana-mana perpustakaan, penulis merasakan masalah kehilangan karya ini perlu dibendung. Naskhah-naskhah manuskrip risalah ini yang telah lama terkubur dalam repositori-repositori manuskrip tempatan harus dikeluarkan dan ditahqiq. Akhirnya, suatu edisi tahqiq Risalat alIstic arat ini patut diterbitkan untuk memudahkan pelajar dan pengkaji menelaah dan membuat semakan serta kajian lanjutan.
\end{abstract}

Kata kunci: Risalat al-Isti c arat, Edisi Tahqiq, Karya Syeikh Ahmad, Ilm al-Isti c arat, Matn al-Bayan. 


\subsection{PENGENALAN}

Syeikh Ahmad al-Fatani merupakan salah seorang ulama Melayu prolifik yang telah mewariskan banyak khazanah ilmu hasil daripada karya-karya kitab yang ditulis oleh beliau dan diterbitkan. Apabila aktiviti penulisan Syeikh Ahmad dibincangkan, didapati bahawa beliau tidak menghadkan pengkaryaannya pada sesuatu bidang keilmuan Islam sahaja, malah khazanah penulisan beliau menunjukkan bahawa Syeikh Ahmad menulis dalam pelbagai bidang keilmuan Islam seperti fekah dan fatwa, akidah dan falsafah, sejarah dan ketamadunan termasuklah bidang-bidang yang berkait rapat dengan ilmu bahasa Arab dan kesusasteraannya seperti nahu, sarf dan balaghah. Dalam bidang nahu dan sarf terutamanya, Syeikh Ahmad dilihat begitu memberi penekanan terhadap penguasaan seseorang penuntut ilmu terhadap kedua-dua bidang ini.

Ujar Syeikh Ahmad: "Dan adalah ilmu ini (yakni ilmu bahasa) sangat besar manfaatnya kerana bahawasa[nya] seseorang apabila mengetahui ia dengan beberapa lughat yang lain dari pada lughat dirinya, nescaya mudahlah baginya mu'amalat dan musahabat dengan sekalian bangsa itu, dan tiadalah memudah-mudahkan mereka itu dengan dia" (Ahmad al-Fatani 1998: 160). Selain itu, beliau juga berkata:
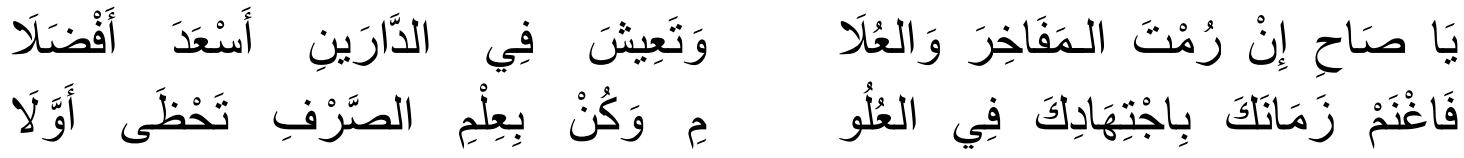

(Ahmad al-Fatani, 2010, hlm. 1)

Sehubungan itu, tujuh karya dalam bidang nahu dan lima karya dalam bidang sarf telah dihasilkan.Tidak ketinggalan juga dalam ilmu balaghah, Syeikh Ahmad turut menggembleng tenaga dengan menghasilkan karya dalam bidang tersebut walaupun ia termasuk bidang yang sangat jarang diceburi oleh ulama Melayu. Masakan tidak, Syeikh Ahmad al-Fatani yang terkenal dengan kemahirannya mempraktikkan al-Asālīb al-Balāghiyyah dalam syair-syair Arabnya sudah cukup untuk menggambarkan kewibawaannya dalam bidang keilmuan ini (Amer Hudhaifah 2015: 34). Walaupun Wan Mohd Shaghir menjelaskan bahawa karya Syeikh Ahmad dalam bidang balaghah ini merupakan antara karya beliau yang terkenal, penulis tidak pernah menemui sebarang naskhah berkaitan Risālat al-Istic ārāt ini, tidak kira dalam bentuk cetakan atau manuskrip yang difotokopi (Amer Hudhaifah \& Salmah 2015: 30). Namun sewaktu penulis menjalankan kajian terhadap manuskrip-manuskrip yang tersimpan di Muzium Kesenian Islam Malaysia (IAMM) di Kuala Lumpur, penulis mendapati sebilangan manuskrip Risālat al-Istic ārāt yang tidak dapat dikesan itu rupanya kini ada dalam simpanan repositori muzium tersebut.

Sehubungan itu, penulis merasakan bahawa manuskrip Arab-Melayu ini perlu diperkenalkan kembali kepada umum agar ilmu yang terkandung dalam helaian-helaian manuskrip tersebut tidak terus terkubur bersama fizikalnya. Terutama sekali apabila kajian berkenaan aplikasi teori al-Majaz al-Mufrad Syeikh Ahmad al-Fatani menurut Risalat al-Isticarat dengan jelas menunjukkan bahawa karya ini mengandungi pelbagai rahsia berkenaan keilmuan ulama Melayu yang perlu dikaji secara lebih mendalam (Amer Hudhaifah \& Salmah, 2015: 31). Justeru itu, suatu edisi tahqiq perlu diterbitkan agar keaslian karya nadir tersebut lebih terjamin selain rahsia-rahsia yang tersembunyi di sebaliknya juga boleh disingkap dan dibahaskan secara lebih tepat dan adil.

\subsection{PENDAHULUAN TAHQIQ}

\subsection{Identiti Karya}

Judul bagi karya ini berbeza-beza berdasarkan catatan naskhah manuskrip dan cetakannya. Wan Mohd Shaghir contohnya telah menaqalkan judul ${ }^{c} I l m$ al-Isticarah dan Matn al-Bayan sedangkan 
bagi Abdullah al-Qari pula, beliau cenderung menaqalkan judul Tadrij al-Sibyan ila Tashwiq alBayan sebagai judul bagi karya ini. Namun menurut pendapat penulis, ia sebenarnya merupakan judul kepada karya Tengku Mahmud Zuhdi yang mengsyarahkan karya Syeikh Ahmad dalam bidang balaghah ini (Wan Mohd Shaghir, 2005: 101). Turut merumitkan lagi apabila penulis mendapati judul yang tercatat pada naskhah manuskrip karya ini juga berbeza-beza. Walau bagaimanapun, judul-judul tersebut didapati berlegar di sekitar makna yang sama sehinggakan penulis berpendapat bahawa judul Risālat al-Istic àrāt wajar dijadikan judul karya ini.

Penulis tidak mendapati sebarang maklumat berkenaan tahun penulisan karya ini daripada kajian Wan Mohd Shaghir, namun menurut suatu catatan pada manuskrip tertua setakat yang ditemui, ia telah dihasilkan sebelum tahun $1312 \mathrm{H}$, iaitu setelah Syeikh Ahmad pulang ke Mekah dan giat menjalankan aktiviti-aktiviti keilmuannya di sana. Secara linguistik, pendapat ini disokong kerana gaya bahasa yang digunakan oleh beliau menampakkan seolah-olah beliau mengajarkan ilmu ini kepada para pelajar. Ujar Syeikh Ahmad: “"نم اعلم أن الاستعارة عند بعضهم إلخ ". Daripada kenyataan ini, watak seorang ulama yang sedang mengajarkan ilmu balaghah kepada pelajar-pelajarnya begitu menyerlah apabila beliau menggunakan Uslüb Ikhbāriy Taclimiy yang turut digunakan oleh beliau dalam Hāshiyat Tashīl Nayl al-Amāni (Ahmad al-Fatani, 1912: 4).

\subsection{Teori dan Metodologi Kajian}

Teori yang diimplimentasikan dalam proses pentahqiqan risalah ini adalah teori Salāh al-Dīn alMunjid dalam sebuah tulisan beliau yang berjudul Qaw $\bar{a}^{c} i d$ Taḥqiq al-Makhțūṭāt. Hal ini kerana teori beliau telah mendapat pengiktirafan meluas daripara sarjana pelbagai bangsa termasuk bangsa Melayu. Pernyataan ini dibuktikan melalui sebuah kertas kerja yang dibentangkan oleh Mat Saad Abdul Rahman pada tahun 1995 berjudul "Tahqiq Manuskrip Arab-Melayu". Walaupun tidak diungkapkan secara jelas, ternyata teori yang diketengahkan oleh beliau dalam kertas kerja tersebut adalah daripada gagasan teori Salāh al-Dīn al-Munjid.

Naskhah yang digunakan dalam proses perbandingan teks pula adalah tiga naskhah manuskrip Risālat al-Istic ārāt yang boleh didapati dalam simpanan repositori Muzium Kesenian Islam Malaysia (IAMM) dengan kod 1998.1.124, 1998.1.216 dan 1998.1.396. Manuskrip berkod 216 telah dipilih untuk dijadikan naskhah utama manakala kedua-dua manuskrip yang lain akan dijadikan teks bandingan. Hal ini kerana antara ketiga-tiga menuskrip yang digunakan, ia merupakan manuskrip yang paling awal dihasilkan di samping ia merupakan naskhah yang paling lengkap, sedangkan kedua-dua manuskrip yang lain didapati telah mengalami beberapa keguguran teks (Salāh al-Dīn alMunjid, 1987: 13). Sehubungan itu, naskhah utama tersebut akan dikenali sebagai naskhah (A) manakala naskhah berkod 396 sebagai naskhah (B) dan naskhah 124 sebagai naskhah (C).

Secara teoritikal, penulis akan mula menyalin kembali karya ini berdasarkan naskhah utama sambil mengekalkan gambaran susunan teks pada naskhah tersebut dengan simbol seperti (آ (1) (ب) ( آ 2) (2) dan seterusnya (Salāh al-Dīn al-Munjid, 1987: 24). Kemudian, hasil salinan tersebut akan dibandingkan dengan kedua-dua naskhah (B) dan (C). Setiap variasi dan pembetulan akan dilaporkan di bahagian Kritikan Apparatus dan setiap nombor yang dinyatakan dalam bab tersebut adalah merujuk kepada nombor yang dinyatakan di dalam teks. Perlu jelas bahawa, hanya kesalahan dan variasi yang signifikan akan diberi penekanan agar nota kaki tidak diberatkan dengan ulasan yang kurang keperluannya bagi kajian ini. Ini bermakna, kesalahan-kesalahan kecil yang mungkin datangnya daripada kejahilan penyalin terhadap kaedah-kaedah bahasa Arab seperti kesalahan dalam menulis perkataan محلّ menjadi محال dalam naskhah (B) dan لائم mada naskhah (A) dan (C) tidak akan dicatat pada bahagian nota kaki (Salāh al-Din al-Munjid, 1987: 16). Jika perlu, suatu kajian lain boleh dilakukan bagi menganalisis kesalahan-kesalahan yang berlaku ini untuk mendapat gambaran penguasaan bahasa Arab orang Melayu terutama pelajar ilmu bahasa Arab. Akhir sekali 
Amer Hudhaifah \& Salmah Ahmad/ UMRAN - International Journal of Islamic and Civilizational Studies. Vol.3, no.2 (2016) 13-21

setelah selesai mentahqiq, sebuah jadual berisi indeks ayat-ayat al-Quran mengikut susunan surah dalam al-Quran akan dikemukakan untuk memudahkan rujukan.

\subsection{Deskripsi Naskhah}

- IAMM 1998.1.216:

Manuskrip yang berukuran $25.4 \times 17.6 \mathrm{~cm}$ ini terdiri daripada 14 halaman bertulis. Walaupun di halaman akhirnya tercatat tahun 1312/1894 sebagai tahun ia dihasilkan iaitu sezaman dengan Syeikh Ahmad, namun penulis tidak dapat memastikan adakah ia daripada tulisan beliau. Walau bagaimanapun, jidar manuskrip ini yang dipenuhi catatan ta'liq bagi matan risalah meyakinkan bahawa kalaupun ia bukan daripada hasil tangan pengarang, sekurang-kurangnya ia pasti pernah digandingkan dengan manuskrip asli. Berbeza dengan kedua-dua naskhah yang lain, manuskrip ini tidak dinyatakan tempat asalnya dan siapakah pemiliknya. Walau bagaimanapun, di halaman judul manuskrip ini, didapati sekeping pelekat yang mempunyai catatan yang menunjukkan bahawa Pusat Islam, Kuala Lumpur (kini dikenali sebagai Jabatan Kemajuan Islam Malaysia) telah menerimanya daripada seorang lelaki bernama Ariffin.

Tulisan pada manuskrip ini adalah cantik dan kemas. Di halaman judul, tulisan yang digunakan adalah khat Thuluth manakala halaman-halaman yang lain menggunakan khat Naskh. Selain matan Risālat al-Istic ārāt, manuskrip ini juga mengandungi 7 bait manżūmah yang mengumpulkan 25 ${ }^{c}$ Alāqāt al-Majāz al-Mufrad milik Syeikh Ahmad al-Fatani. Ketujuh-tujuh bait manzūmah ini ditulis pada halaman kedua dan ketiga manuskrip dan di sekitarnya penuh dengan $t a^{c} l i q \bar{a} t$ yang juga milik beliau. Selain itu, di halaman terakhir iaitu halaman penutup pula, tercatat 3 bait manz̧ümah yang menghimpunkan $10{ }^{c}$ Alāqāt al-Majāz al-Mufrad milik seorang ulama balaghah yang bernama Ahmad ibn Ahmad al-Sujāciy al-Azhariy (w.1197). Manuskrip ini lengkap dan fizikalnya terjaga rapi kerana telah melalui proses perawatan dan pemeliharaan.

- IAMM 1998.1.396

Manuskrip kod ini sebenarnya terdiri beberapa manuskrip berbeza tetapi telah dirangkum dalam satu simpanan (Handlist of Malay Manuscripts in the Islamic Arts Museum Malaysia: Jakim Collection. Vol. 1. 2010: 87). Walau bagaimanapun, manuskrip yang berkaitan dengan kajian tahqiq ini hanyalah manuskrip pertama daripada kumpulan manuskrip tersebut. Manuskrip ini khususnya terdiri daripada 7 halaman bertulis dengan saiz $25 \times 17.5 \mathrm{~cm}$ dimiliki oleh Muhammad Seman bin Ahmad dari negeri Patani. Catatan pada bahagian kolofon di akhir halaman manuskrip ini menunjukkan bahawa ia telah disalin di Mekah pada hari Sabtu dalam tahun 1315/1897 iaitu sewaktu Syeikh Ahmad masih hidup. Jenis tulisan yang digunakan adalah khat Naskh yang bersaiz lebih kecil berbanding kedua-dua manuskrip yang lain. Walaupun terdapat kesan-kesan hangus akibat suhu di samping kesan koyakan yang berlaku di birai helaian manuskrip, namun ia tidak menjejaskan tulisannya. Malah, tulisan padanya masih dapat dibaca dengan mudah termasuk beberapa ta'liqat ringkas di antara baris-baris matan. Sehubungan itu, kondisi fizikalnya boleh dijustifikasikan sebagai lengkap dan baik.

\section{- IAMM 1998.1.124}

Manuskrip ketiga yang berkod IAMM 1998.1.124 ini pula berukuran $25.5 \times 18 \mathrm{~cm}$ dan terdiri daripada 9 halaman bertulis. Menurut catatan pada bahagian judul, manuskrip bertulisan khat Thuluth hampir pada keseluruhan teksnya ini adalah milik seorang lelaki bernama Abdullah bin Haji yang berasal dari negeri Patani. Berbeza dengan kedua-dua manuskrip yang telah dideskripsi, manuskrip naskhah ini tidak dapat dikenal pasti dimanakah ia dihasilkan selain ia juga tidak diketahui bilakah penyalinannya berlaku. Walau bagaimanapun, kondisi fizikal manuskrip ini yang 
kelihatan lebih utuh dan elok tanpa sebarang kerosakan menampakkan bahawa ia adalah jauh lebih baharu berbanding kedua-dua manuskrip Risālat al-Istic ārātyang lain.

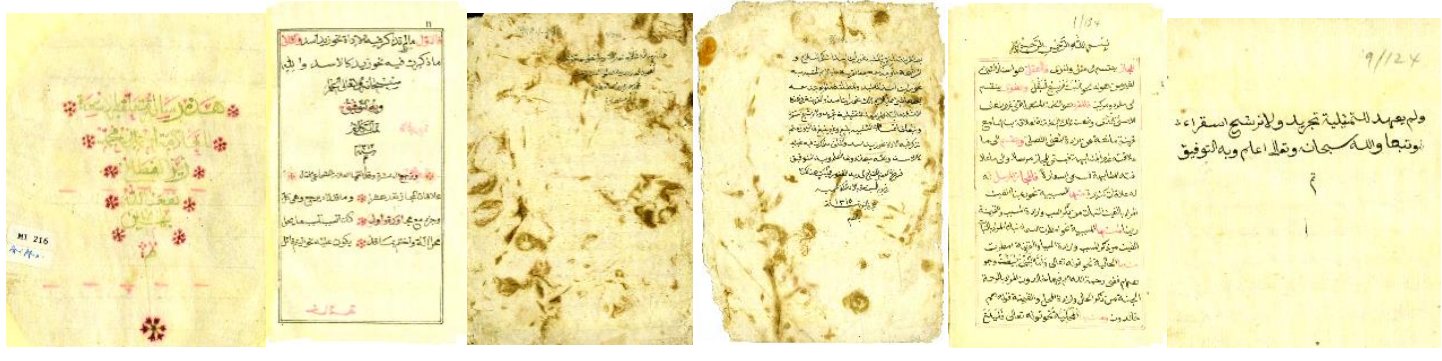

Rajah 1: Halaman bertulis yang pertama dan terakhir bagi ketiga-tiga manuskrip berkod 216 (paling kiri), 396 (tengah) dan 124 (paling kanan).

\subsection{EDISI TAHQIQ}

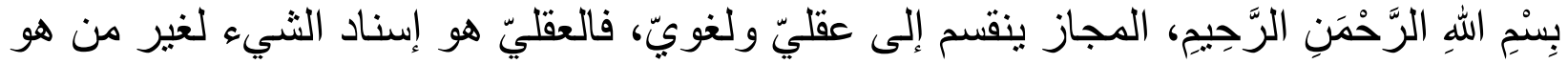

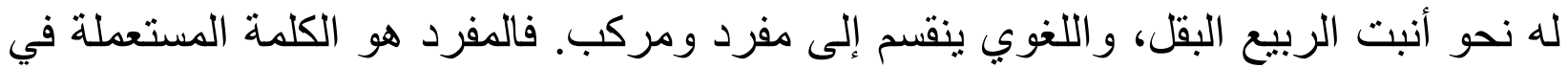

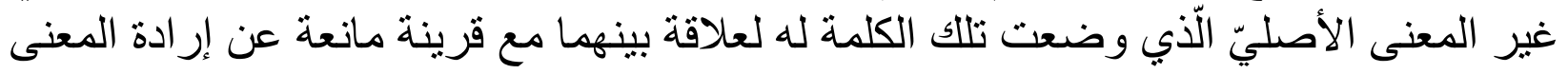

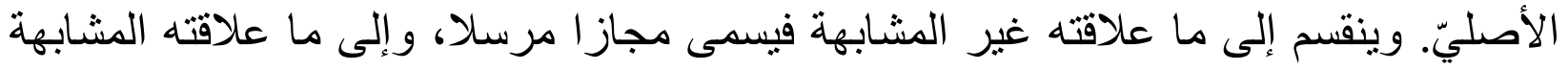
فيسمّى استعارة.

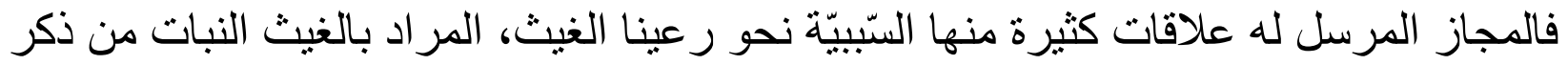

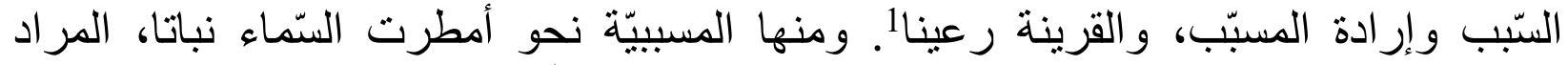

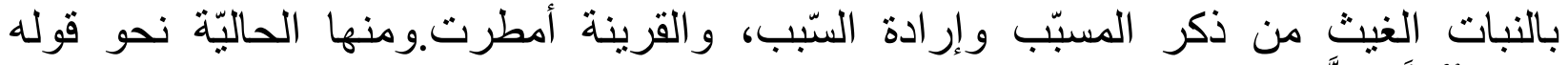

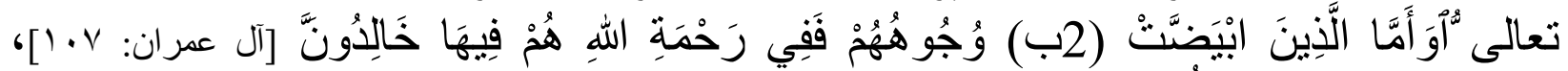

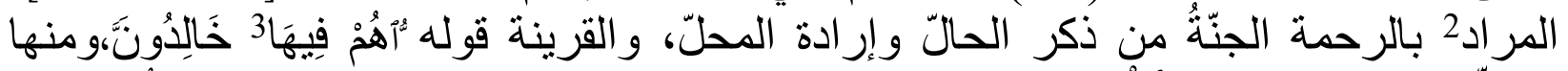

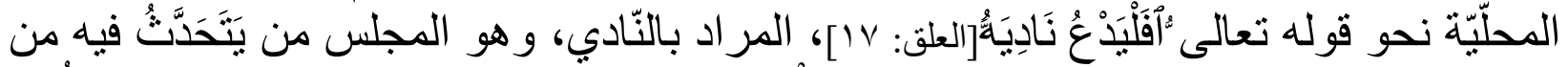

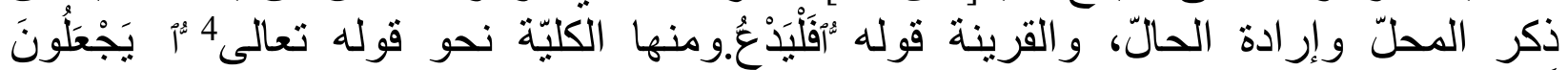

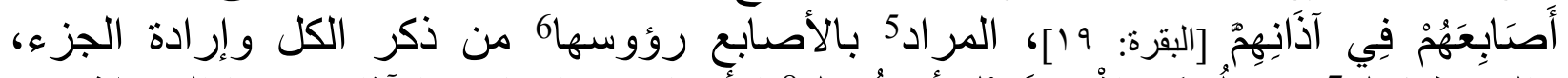

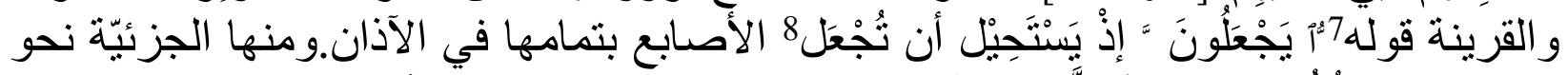

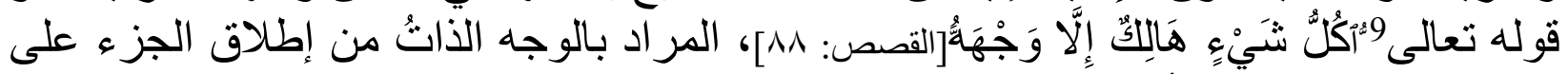

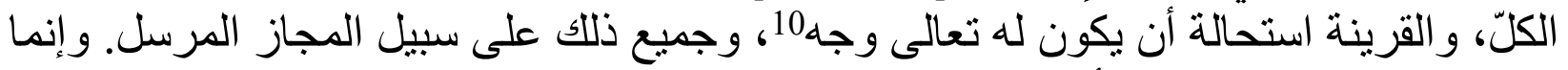

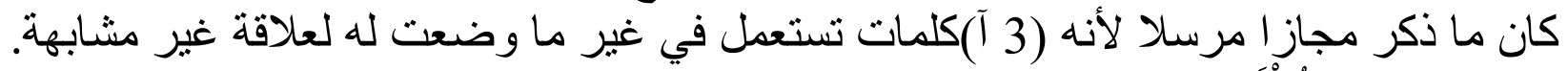

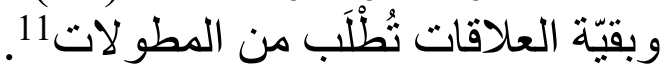

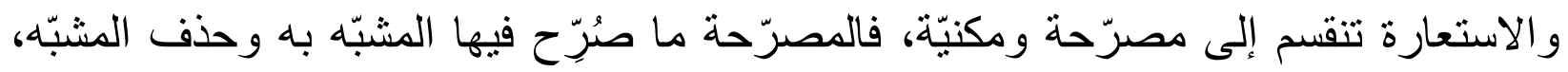
و المكنية عكسها، و هو ما حذف فيها المشبّه بهـ وذكر المشبّه.

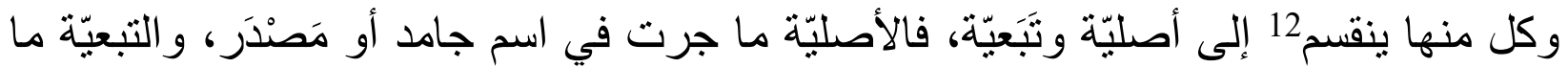

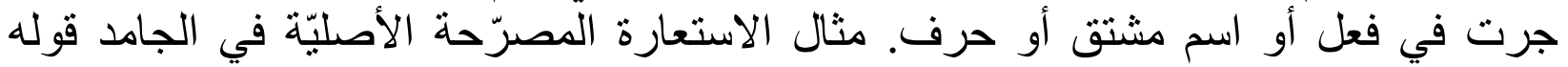




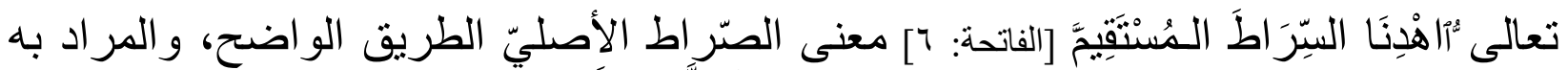

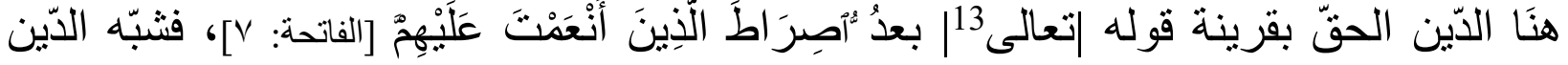

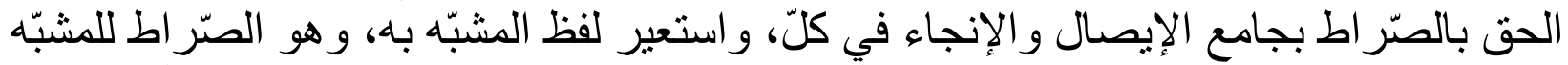

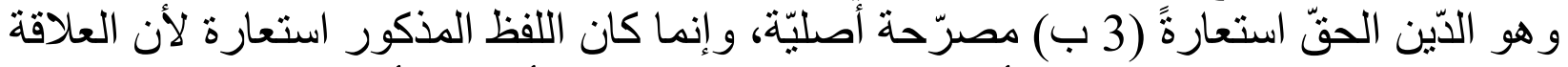

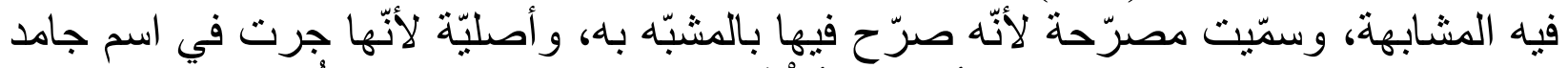

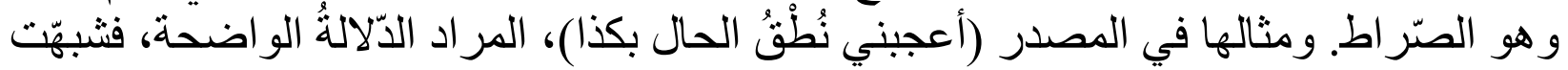

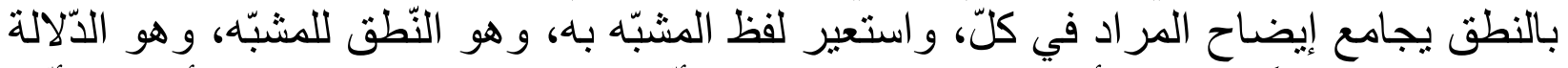

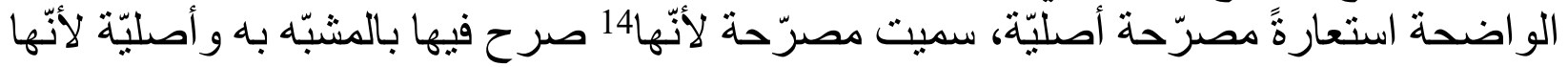

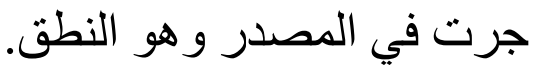

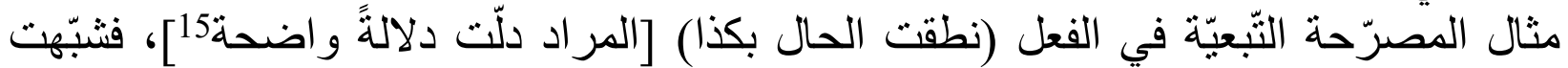

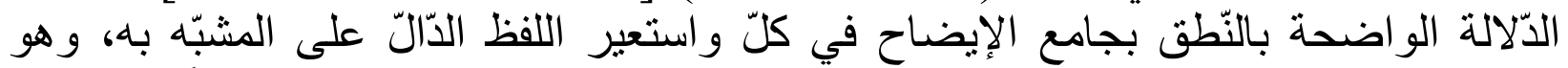

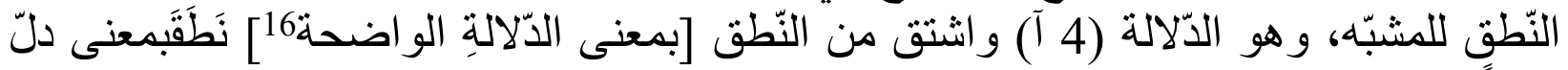

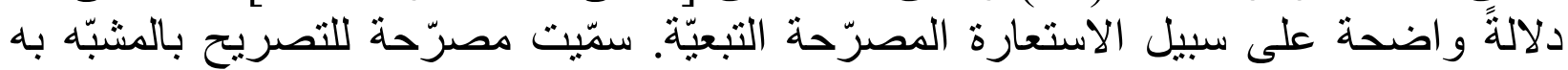

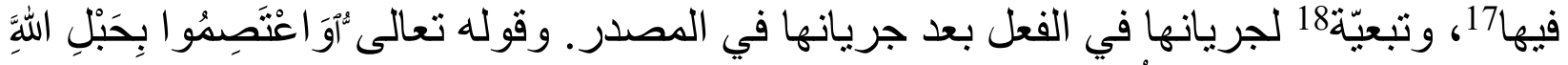

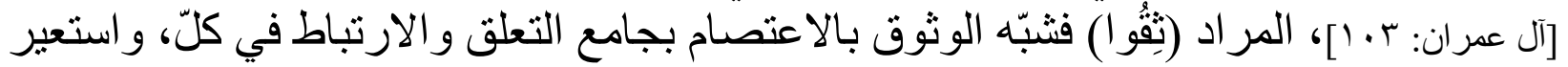

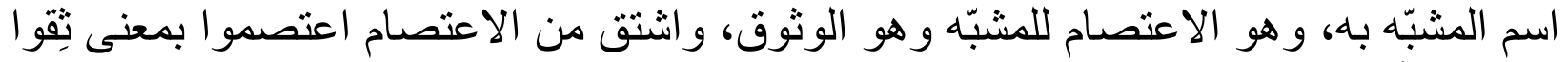

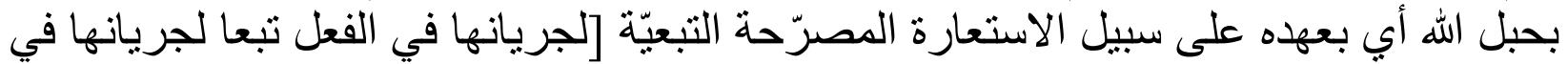

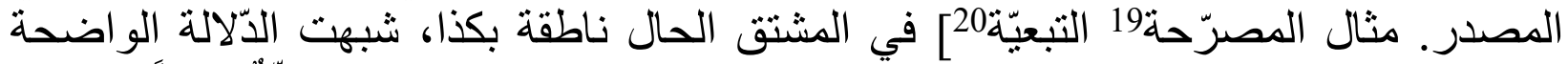

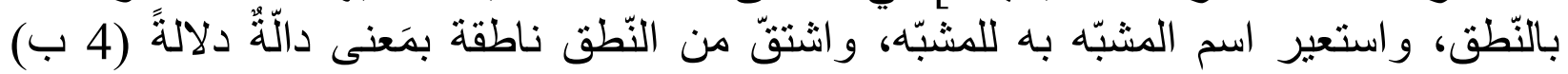

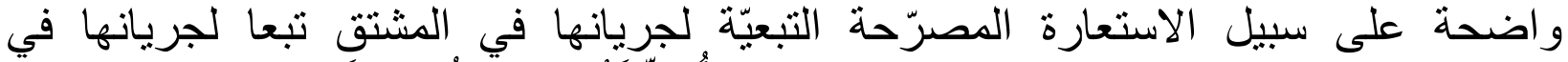

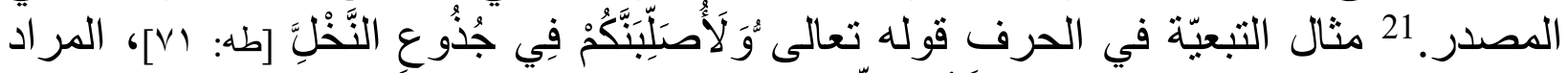

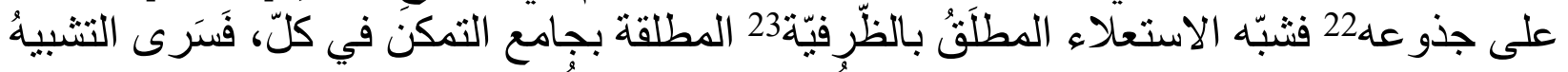

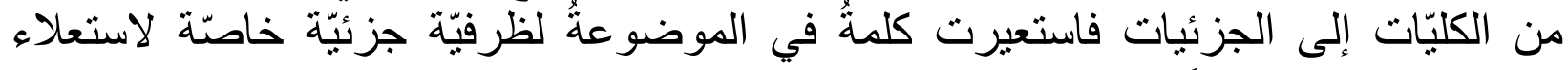

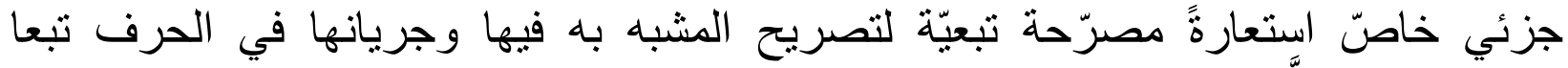
لجريانها في متعلَّهِه.

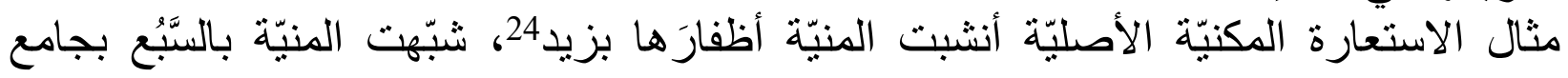

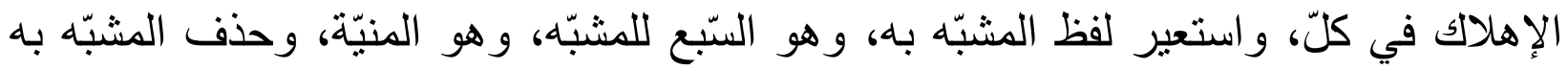

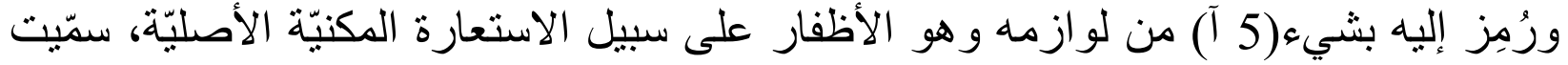

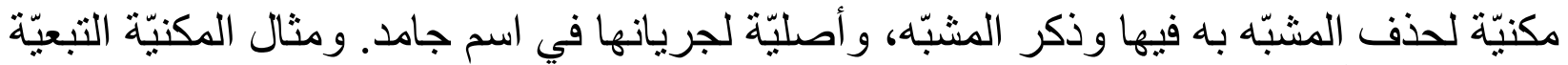

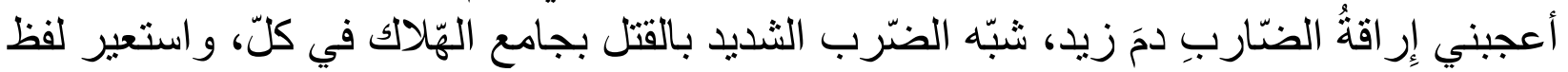

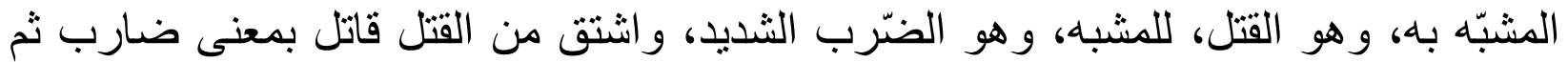

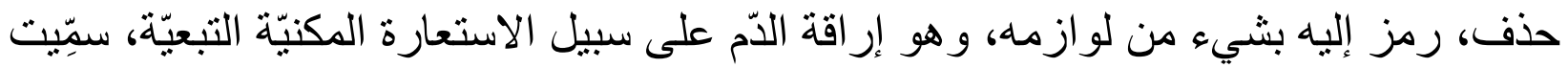
مكنيّة لحذف المشبّه به، وتبعية لجريانها في المشتقِّ بعد جريانها في الـمَصندَرَ. 
ثم اعلم 25 أن الاستعارة عند بعضهم تتقسم أيضا إلى تحقيقية، وهي ما كان المثبّه فيه محقّّا حسّا

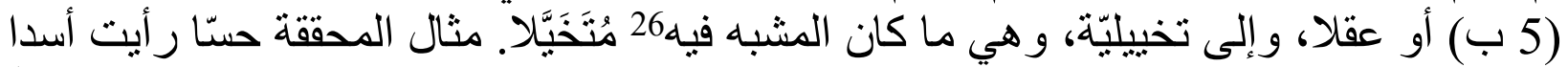

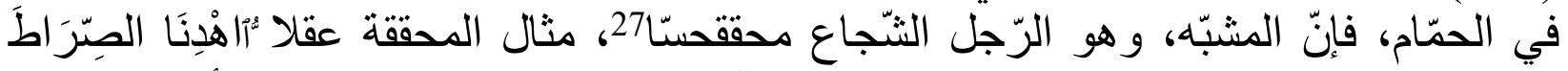

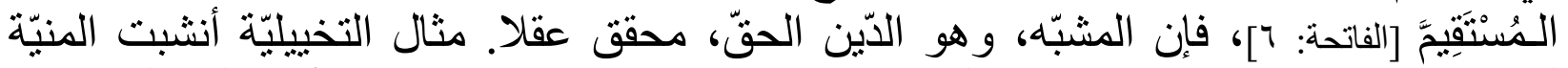

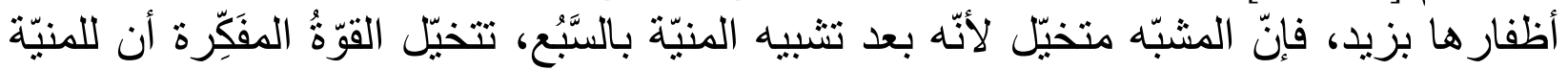

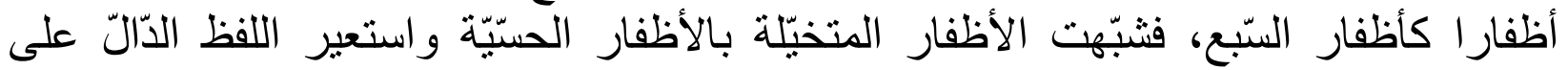

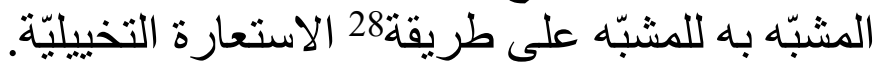

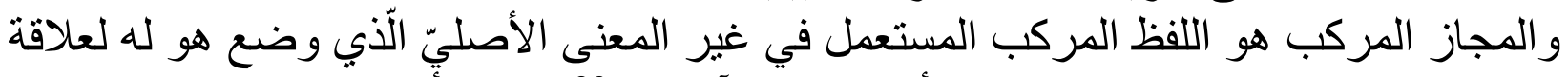

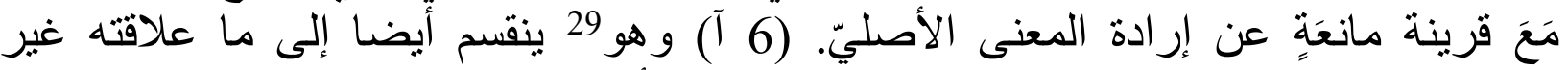

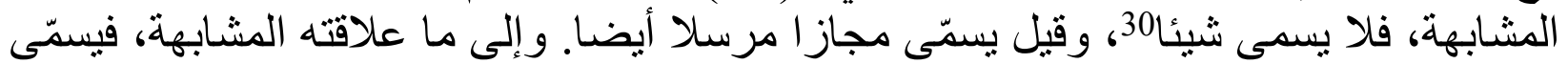
استعارة تمثيلية، وهي تتقسم أيضا إلى مصرّحة ومكنيّة. مثنال التمثيليّة المصرّحة قورة لهم إنّي

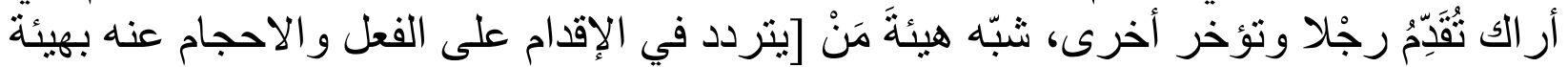

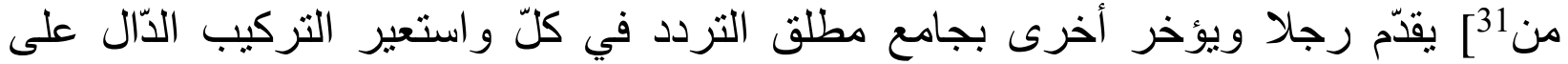

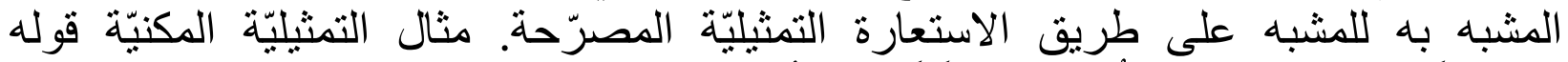

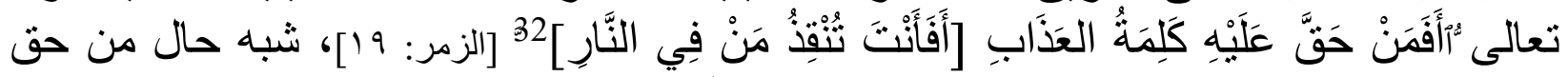

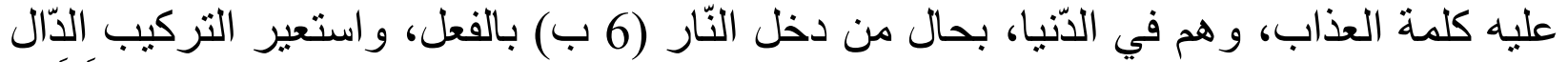

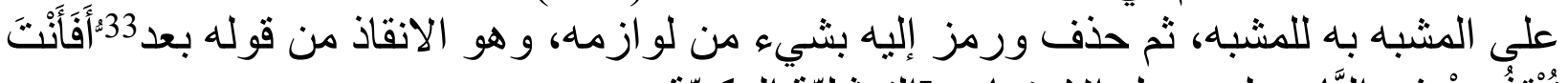

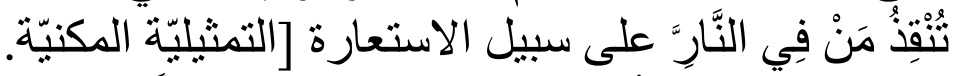

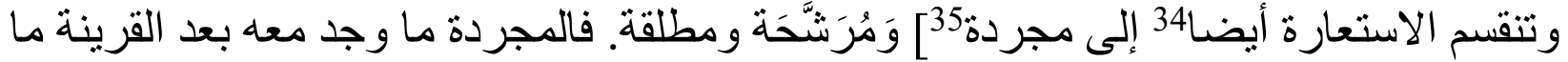

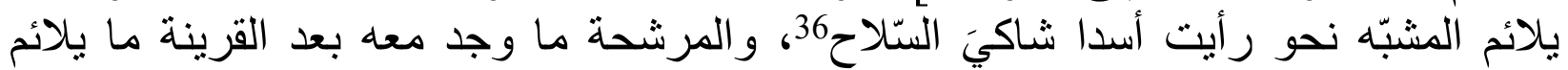

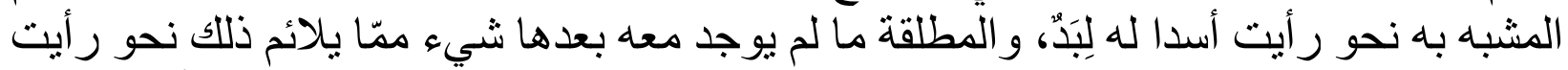

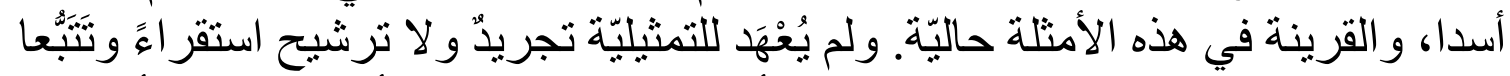

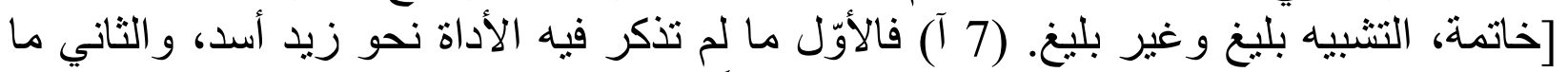

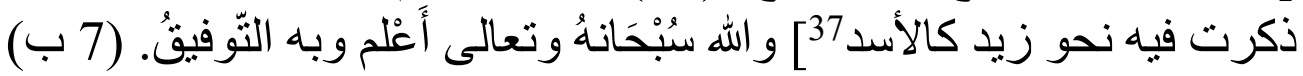

\subsection{KRITIKAN APPARATUS}

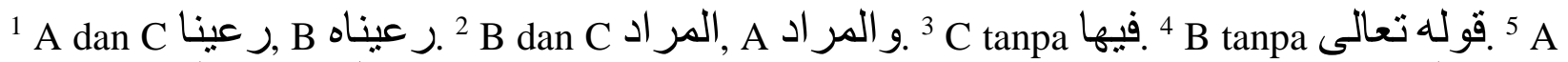

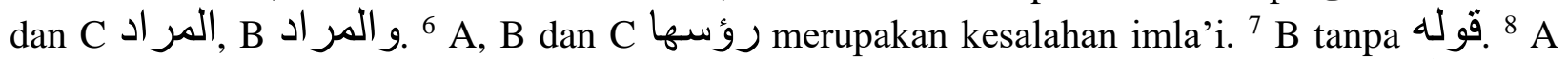

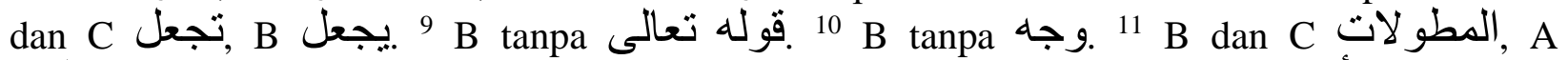

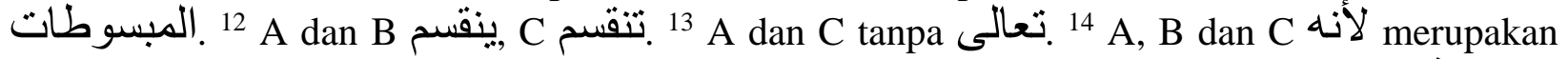

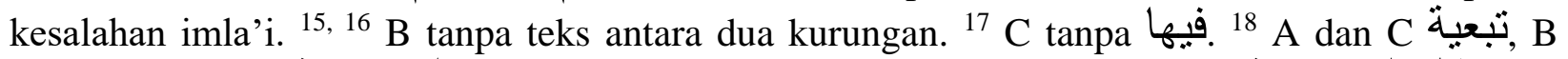

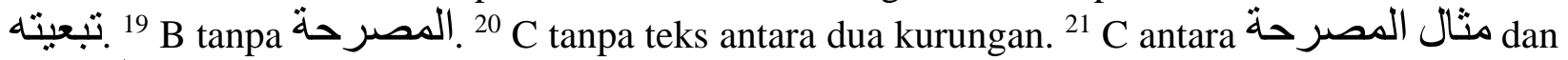
terdapat pengulangan teks:

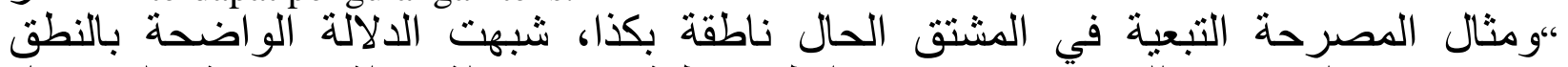
و استعير اسم المشبه به للمشبه واشتق من النطق ناطقة بمعنى دالة دلالة واضحة واضثة على سبيل

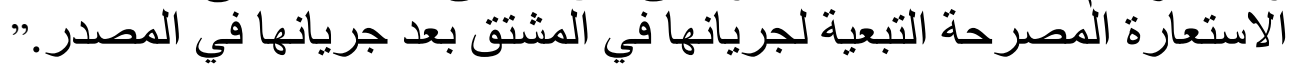




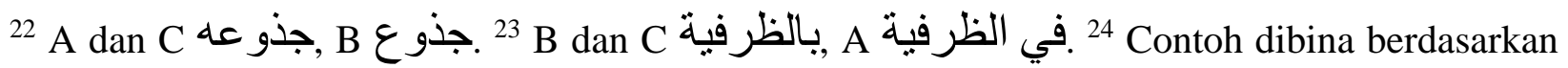
bait Abu Dhu'ayb al-Hudhali:

وَإِذَا

(Abu Dhu'ayb al-Hudhaliy, 1965: 3)

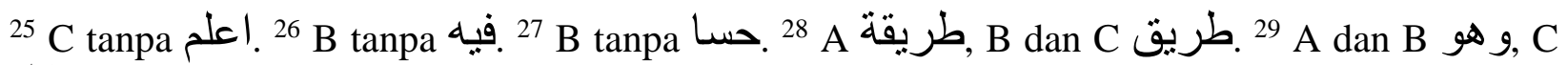

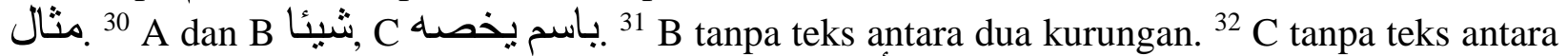
dua kurungan. ${ }^{33} \mathrm{~A}$ dan B tanpa بعد ${ }^{34} \mathrm{~B}$ tanpa أيضـا ${ }^{35} \mathrm{C}$ tanpa teks antara dua kurungan. ${ }^{36}$ Contoh dibina berdasarkan bait Zuhayr Ibn Abi Sulma:

لََدَى ل أَسَدِ

(Zuhayr Ibn Abi Sulma, 1988: 108)

${ }^{37} \mathrm{C}$ tanpa teks antara dua kurungan.

\subsection{INDEKS AYAT AL-QURAN}

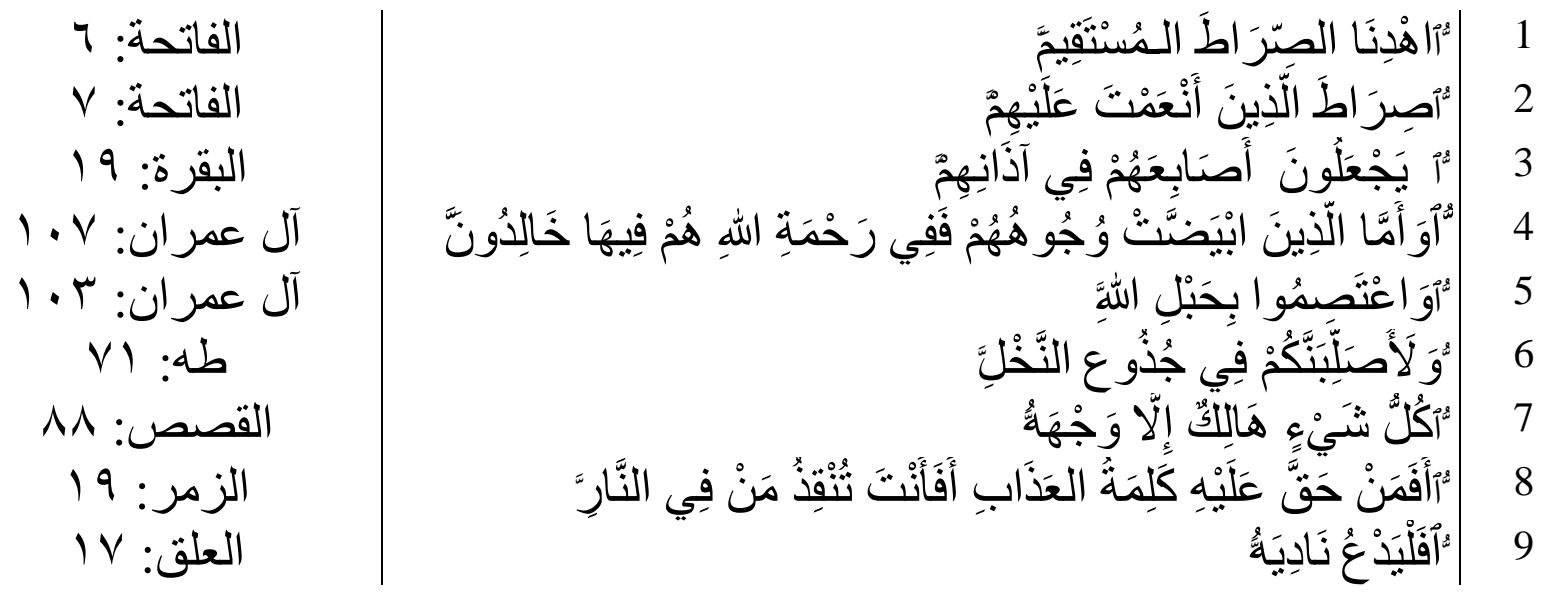

\subsection{KESIMPULAN}

Dari edisi tahqiq Risālat al-Istic ārāt Syeikh Ahmad al-Fatani ini, dapat disimpulkan bahawa ketigatiga manuskripnya yang disimpan di Muzium Kesenian Islam, Kuala Lumpur tidak selamat daripada perbezaan riwayat dan kesalahan penulisan, terutama sekali kedua-dua naskhah (B) dan (C). Ia terlibat dengan banyak keguguran naskhah akibat daripada kesilapan penyalin yang kadang-kadang tergesa-gesa sewaktu proses penyalinan. Sehubungan itu, karya ini sememangnya wajar ditahqiq agar keasliannya boleh dilestarikan sekaligus boleh membuka peluang kepada para sarjana untuk merujuk dan menjadikannya sebagai subjek kajian mereka. Di samping itu, kewujudan manuskrip karya ini cukup untuk menjadi bukti bahawa walaupun Alam Melayu berada jauh dari negara-negara Arab, namun pendidikan bahasa Arab sangat ditekankan sehingga ia dianggap begitu penting sebelum memasuki bidang-bidang keilmuan Islam yang lain, tidak kira dalam bidang tatabahasa bahasa Arab mahupun dalam bidang sastera dan retorika seperti bidang balaghah. Walau bagaimanapun, kebanyakan karya ulama Melayu dalam bidang ini seperti Lubāb al-Bayān karya Syeikh Nawawi Banten, al-Tacliq Ala al-Risālat Fī al-Bayān karya Syeikh Ahmad Nahrawi Banyu Mas, Sharh Tadrīj al-Șibyān karya Tengku Mahmud Zuhdi dan Huṣn al-Ṣiyāghat Sharh Durūs al-Balāghah karya 
Amer Hudhaifah \& Salmah Ahmad/ UMRAN - International Journal of Islamic and Civilizational Studies. Vol.3, no.2 (2016) 13-21

Syeikh Yasin al-Fadani tidak diketahui umum. Sehubungan itu, penulis mencadangkan agar kitabkitab ini juga ditahqiq dan dikaji supaya ia tidak terus kelam ditelan zaman.

\section{Rujukan}

Al-Qur'ān al-Karīm, (2008). Muṣhaf al-Madīnah. Madinah: Majmac al-Malik Fahd lì Ṭibā'at al-Muṣhaf al-Sharif.

Abū Dhu'ayb al-Hudhaliy. (1965). Diwān al-Hudhaliyyin. Al-Qahirah: Al-Dār al-Qawmiyyat lì al-Tibācat wa al-Nashr.

Ahmad al-Fatani. (1912). Tashil Nayl al-Amāni Fì Sharh ${ }^{c}$ Awāmil al-Jurjāniy. Makkah: Mațbacat al-

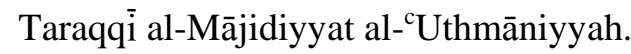

Ahmad al-Fatani. (1998). Hadiqatul azhar war rayahin: Asas teori takmilah sastera Melayu-Islam (Jil. 1). Kuala Lumpur: Khazanah Fathaniyah.

Ahmad al-Fatani. (t.th). Manuskrip matn al-madkhal fi 'ilm al-șarf: Kumpulan risalah nahu \& sharaf. Kuala Lumpur: Khazanah Fathaniyah.

Amer Hudhaifah \& Salmah Ahmad. (2015). Keindahan gaya bahasa syair Rawd al-Amāni: Aplikasi teori ${ }^{c}$ ilm al-majāz al-mufrad Syeikh Ahmad al-Fatani dalam puisi pujian \& pengharapan beliau kepada Sultan Zainal Abidin III. Prosiding Nadwah Ulama Nusantara (NUN) VI. Bangi. Fakulti Pengajian Islam, Universiti Kebangsaan Malaysia.

Jabatan Agama Islam Malaysia. (2010). Handlist of Malay manuscript in the Islamic Arts Museum Malaysia: JAKIM Collection (Vol. 1). Kuala Lumpur: Muzium Kesenian Islam Malaysia.

Zuhayr Ibn Abī Sulmā. (1988). Diwān Zuhayr Ibn Abì Sulmāa. Tahqiq Ali Hasan Fā̄ur. Beirut: Dār alKutub al-'Ilmiyyah. 